\title{
Study on Stability of Sludge and Landfill by Composite Conditioner with Calcium Superphosphate
}

\author{
Shijun Yin, Jian Kang \\ Shenyangjianzhu University, Shenyang, China
}

Keywords: Calcium Superphosphate; Sludge; Conditioner

\begin{abstract}
The moisture content of sludge in sewage plant is $80 \%-85 \%$,In order to disposal, sludge need to be deep dewatering. The test added in composite conditioner with calcium superphosphate in different proportion. Measure the moisture content ,ph and volatile organic matter. The experimental results show that, Composite conditioner can improve the performance of sludge dewatering effectively, The moisture content of sludge decreased to less than 60\%,ph of Sludge drop below 10,the addition of calcium superphosphate is prevented the loss of organic matter.
\end{abstract}

\section{Introduction}

With the development of the city in recent years, The number of urban sewage plant increases year by year. Sewage treatment industry has achieved great success. ${ }^{[1]}$ Increase the rate of water and resulting in a large amount of activated sludge,Treatment and disposal of Most of Sewage treatment sludge cannot be effectively. In the case of hydrological environment, atmosphere and soil and other natural environment poses a great risk and burden. At the same time it cause serious secondary pollution to the environment. ${ }^{[2]}$

Studies have shown that,A sewage treatment plant sludge moisture content is still around $80 \%$ to $85 \%$,the late treatment still encountered great difficulties. There are three common ways of depth of sludge dewatering,they are Thermal drying,biological drying and chemical drying. ${ }^{[3]}$ The chemical added to high moisture content of sludge,It in improving the performance of sludge dewatering, and also can change the $\mathrm{pH}$ of treated sludge, volatile organic matter content and percentage of heavy metals, This method is called the chemical drying. Chemical conditioners have obvious effect, simple equipment, convenient operation and so on merits, so the depth of the sludge dewatering process widely used in chemical methods. ${ }^{[4]}$ One-component sludge chemical conditioners are often difficult to achieve the ideal effect of dehydration,So in recent years, researchers began to develop composite conditioner or a variety of conditioner compound combination, to increase the depth of the sludge dewatering performance. ${ }^{[5]}$ Quick Lime is a common chemical sludge conditioner, its main composition is $\mathrm{CaO}$, Quick Lime has been widely used in the sludge dewatering processing, But $\mathrm{pH}$ of the sludge of treating by Quick Lime is too high,Increase the difficulty of the post-processing of sludge. $s$ a common industrial waste residue of fly ash, because of its low price, itself and are easy to dehydration compounds, often with quick lime coupled to form a composite conditioners. Acid calcium superphosphate is a common fertilizer, its main component is ( $\mathrm{Ca}(\mathrm{H} 2 \mathrm{PO} 4) 2)$,Calcium superphosphate with fly ash, lime mixed composite conditioner cooperation, can effectively solve the higher $\mathrm{pH}$ problem caused by adding lime. The $\mathrm{Ca} 2+$ of Calcium superphosphate can react with organic ingredients in the sludge,changing structure of the sludge flocs and promoting the sludge dewatering. In addition,It can improve the problem of organic matter reduction in sludge and reduce the difficulty of the late sludge disposal,The sludge can be used as organic fertilizer landfills.

\section{Materials and methods}

\subsection{Experimental chemicals and experimental apparatus}

Sludge of experiment from excess sludge of shenyang northern sewage treatment plant,The moisture content is about 83.5\%,Experimental chemicals are lime, secondary fly ash and calcium superphosphate for industry. The experimental apparatus are shown in table 1 


\begin{tabular}{ccc}
\hline Number & Apparatus & Model \\
\hline 1 & Electronic analytical balance & FA1004N \\
2 & Electric thermostaticdrying oven & DHG-9246 \\
3 & Desk centrifuge & TDL-5-A \\
4 & Circulating water vacuum pump & SHB-B95A \\
5 & PH meter & SPECTROPHOTOMETER \\
6 & Oscillation incubator & ZDP-150 \\
7 & Six automatic lifting electric mixer & JJ-4A \\
8 & Muffle furnace & -- \\
\hline
\end{tabular}

2.2 Methods

2.2.1 Sludge dewatering experiments

Mix the Quick lime, fly ash and calcium superphosphate as a conditioner ,Reaction of the chemical compound conditioner see below type

$$
\begin{gathered}
\mathrm{CaO}+\mathrm{H}_{2} \mathrm{O}=\mathrm{Ca}(\mathrm{OH})_{2} \\
\mathrm{Ca}\left(\mathrm{H}_{2} \mathrm{PO}_{4}\right)_{2}+2 \mathrm{Ca}(\mathrm{OH})_{2}=\mathrm{Ca}_{3}\left(\mathrm{PO}_{4}\right)_{2}+4 \mathrm{H}_{2} \mathrm{O}
\end{gathered}
$$

As can be seen from the chemical equation,Quick lime and calcium superphosphate adequately reaction, The molar mass ratio is $2: 1,2 \mathrm{n}(\mathrm{CaO})=\mathrm{n}(\mathrm{Ca}(\mathrm{H} 2 \mathrm{PO} 4) 2)$, The quality ratio is 1:2. Considering the conditioner of the economy,Fly ash is still as a main component of composite conditioner,Fixed the quality of fly ash. The total mass of composite conditioner is set to 8g 20g. The dosing scheme is shown in Table 2

\begin{tabular}{llll}
\hline Conditioner & Fly ash & Quick lime & $\begin{array}{l}\text { calcium } \\
\text { superphosphate }\end{array}$ \\
\hline 1 & $8 \mathrm{~g}$ & $0.5 \mathrm{~g}$ & $1 \mathrm{~g}$ \\
2 & $8 \mathrm{~g}$ & $1 \mathrm{~g}$ & $2 \mathrm{~g}$ \\
3 & $8 \mathrm{~g}$ & $1.5 \mathrm{~g}$ & $3 \mathrm{~g}$ \\
4 & $8 \mathrm{~g}$ & $2 \mathrm{~g}$ & $4 \mathrm{~g}$ \\
5 & $8 \mathrm{~g}$ & $2.5 \mathrm{~g}$ & $5 \mathrm{~g}$ \\
6 & $8 \mathrm{~g}$ & $3 \mathrm{~g}$ & $6 \mathrm{~g}$ \\
\hline
\end{tabular}

\subsubsection{Moisture content of sludge}

The chemical conditioning of sludge into the Buchner funnel. Under constant pressure, the use of circulating water vacuum pump and vacuum suction filter device filter sludge for 20 minutes, When Buchner funnel bottom almost no more water,Take out the sludge cake placed in petri dishes and weigh it. Put the dish into the oven drying at $105 \mathrm{C}$ for 6 hours, Check the quality of it, Calculate the moisture content.

$$
\omega=\frac{M_{1}-M_{3}}{M_{1}-M_{2}} \times 100 \%
$$

$\omega$ - -The sludge moisture content, $\%$;

M1 - - The quality of the watch glass and wet sludge combined,g;

M2- - The quality of the watch glass,g;

M3- - The quality of the watch glass and dried sludge combined,g.

2.2.3 Determination of $\mathrm{pH}$

Put the dried sludge into the grinding machine for grinding,and put the sludge powder sieving,Each group take $5 \mathrm{~g}$,Put the $5 \mathrm{~g}$ dried sludge into a $150 \mathrm{ml}$ conical flask,Add $50 \mathrm{ml}$ distilled water. Seal it and placed in the oscillation incubator. Oscillation it of $4 \mathrm{H}$ at room temperature, then Centrifuge for 5 minutes,extract supernatant liquid,determination the $\mathrm{pH}$ with $\mathrm{PH}$ meter.

\subsubsection{Determination of Volatile organic matter}

Weigh accurately quality of dry sludge at the temperature of $105^{\circ} \mathrm{C}$ and record it. Then put the dry sludge into the muffle furnace at $600^{\circ} \mathrm{C}$ burning for an hour. Remove it and cool to $100^{\circ} \mathrm{C}$,Put it in the constant temperature drying box drying for 1.5 hours at $105^{\circ} \mathrm{C}$. Weigh the remaining solid mass. 


$$
\rho=\frac{S_{1}-S_{2}}{S_{1}} \times 100 \%
$$

S1- - The quality of dried sludge, g;

S2 —- The quality of sludge ash after burning, $g$.

\section{Results and discussion}

\subsection{Moisture content of the sludge}

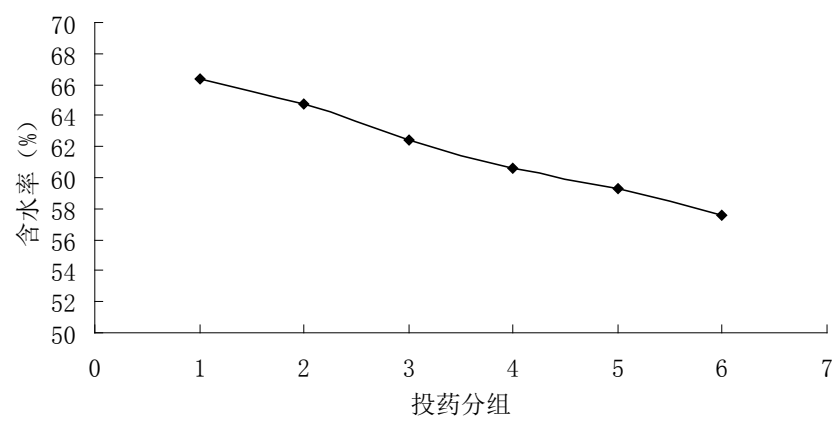

Mixed fly ash, lime and calcium superphosphate,As a composite conditioner added into $100 \mathrm{~g}$ sludge for conditioning,According to table 2 add,Vacuum the sludge which is reacted. The moisture content of sludge is $66.54 \%, 64.291 \%, 62.55 \%, 60.71 \%, 59.19 \%, 57.52 \%$. The moisture content of sludge decreased with the increase of quality conditioner. Two chemical conditioner in others experiment compared to the same quality of three chemical conditioner,The moisture content of the sludge is very close. The quality of conditioner in Experiment 5 and 6 is $15.5 \mathrm{~g}$ and $17 \mathrm{~g}$, the moisture content of the sludge is $59.19 \%$ and $57.52 \%$,The moisture content of sludge is in line with landfill standards. It is noteworthy that three kinds of chemicals can not be directly mixing and adding,Fly ash and lime composite conditioner is added first, When they were fully reaction,add Calcium superphosphate in sludge.

$3.2 \mathrm{pH}$ of the sludge

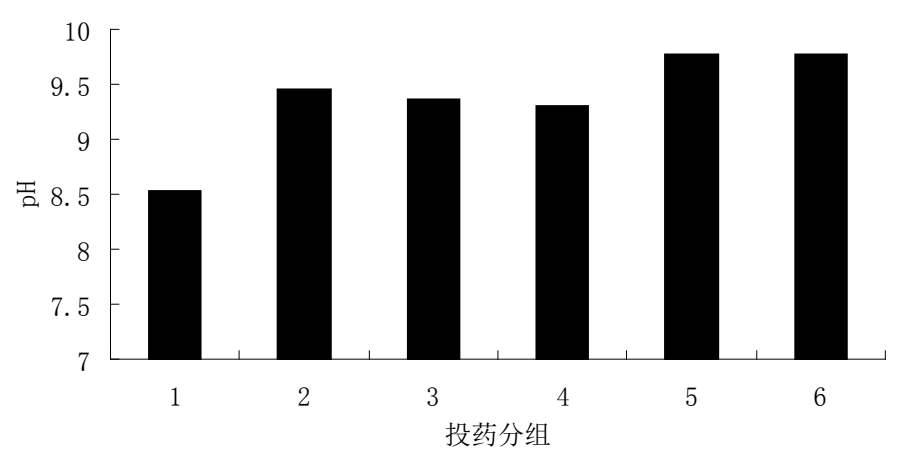

With three chemcals conditioner of sludge by Vacuum filtration,the $\mathrm{pH}$ of the sludge is 8.25, 9.39, 9.44, 9.46, 9.73, 9.71. The sludge is weak alkaline. Fly ash $\mathrm{pH}$ value close to 7,CaO of Quick lime and water of sludge produce a chemical reaction, The reaction produces $\mathrm{Ca}(\mathrm{OH}) 2, \mathrm{pH}$ of Sludge rise rapidly,Calcium superphosphate is a kind of acidic fertilizer,the $\mathrm{pH}$ is about 2 3,The main component of calcium superphosphate is $\mathrm{Ca}(\mathrm{H} 2 \mathrm{PO} 4) 2$, $\mathrm{Ca}(\mathrm{H} 2 \mathrm{PO} 4) 2$ can react with $\mathrm{Ca}(\mathrm{OH}) 2$, This reaction can reducet the $\mathrm{pH}$ of sludge,Reduce the environmental pollution caused by the sludge. 


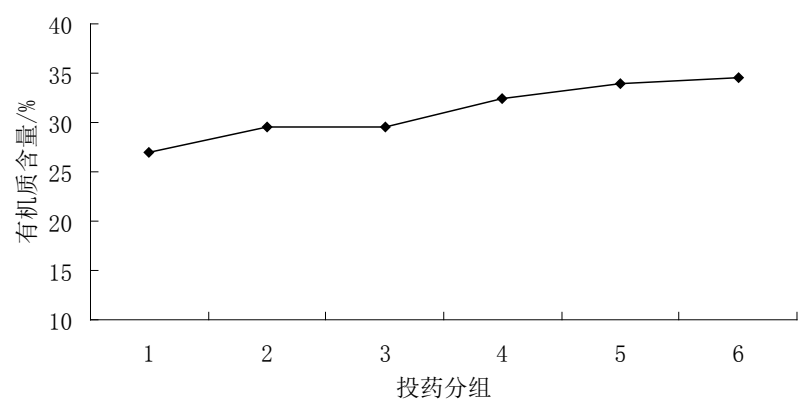

The sludge with three chemicals conditioner is dewatered in muffle furnace, the organic matter of sludge in six experiments are respectively $27.06 \%, 29.43 \%, 29.75 \%, 32.65 \%$, $33.91 \%$, $34.71 \%$. the organic matter of sludge without conditioners is $39 \%$. Adding the conditioner in sludge, There is a chemical reaction between Organic matter of sludge and conditioner , To reduce the content of organic matter of the sludge, The sludge added by Fly ash and Quick lime as composite conditioner,the content of organic matter will be reduced to $20 \%$, the conditioners mixed calcium superphosphate can reduce the loss of organic matter. the organic content of experimental group 4, 5 , 6 are more than 30\%. The content of organic matter in such a numerical approach of sludge without conditioners. Prove that the composite conditioner with three chemicals can make sludge dewatering smoothly and reduce the loss of organic matter.

\section{Conclusion}

1. Fly ash, Quick lime, Calcium superphosphate composite conditioner can effectively reduce the moisture content of sludge, When the quality of fly ash , Quick lime and Calcium superphosphate are $8 g, 3 g$ and $6 g$, the moisture content of sludge decreased to $57.53 \%$.

2. Calcium superphosphate is an acidic fertilizer,mixed with Fly ash, Quick lime formed a Composite conditioner,This conditioner can effectively reduce the $\mathrm{pH}$ of sludge,To reduce pollution of soil and environment in landfill dispose.

3. Calcium superphosphate is an acidic fertilizer, Added into the sludge can effectively reduce the loss of organic matter.

\section{References}

[1]Dong Tao,Qian Qiulan,Chemical Conditioning and Deep Dewatering of Sludge[J].Cement Technology,2013,2:22-25

[2]J. A. Müller.Pretreatment Processes for the Recycling and Reuse of Sewage Sludge[J]. Water Science and Technology ,2000

[3]Jung-Eun Lee.The effect of the addition of fly ash to municipal digested sludge on its electroosmotic dewatering.J Mater Cycles Waste Manag,2011,13:259-263

[4]Krishnamurthy S.Viraraghanan T.Chemical conditioning for dewatering municipal wastewater sludges.Energy Sources,2005,27(1-2)

[5]Liang Peng,Huang Xia,Research progress on sludge reduction technologies[J].Technique and Equipment for Environmental Pollution Control,2003,4:47-50 